\title{
Maxillary Bilateral Supernumerary Premolars in an 18 year old Adult: A Case Report
}

\author{
Dr.Nishant Gupta ${ }^{1}$, Dr.Gunjan Gupta ${ }^{2}$, Dr.AdarshVerma ${ }^{3}$, \\ Dr. Anuj Satija ${ }^{4}$ \\ ${ }^{1,4}$ Lecturer, Dept. of Orthodontics, Shree Bankey Bihari Dental College. \\ ${ }^{2}$ Sr. Lecturer, Dept. of Peridontics, Shree Bankey Bihari Dental College. \\ ${ }^{3}$ Dentist at Verma Dental World, Patparganj.
}

Abstract: An 18 yr old adult presented with bilateral supernumerary premolars in maxillary $2^{\text {nd }}$ molar region. Early diagnosis and management were done to correct the orthodontic problems.

Keywords: Maxillary, Premolar, Supernumerary

\section{Background:}

\section{Introduction}

Supernumerary tooth/teeth is a frequently observed developmental disturbance in clinical practice. These teeth may be impacted or may be seen in oral cavity and may resemble molars, premolars or incisors or may not resemble any of the teeth.

These teeth may lead to development of malocclusion by hindering the path of eruption of the erupting teeth leading to ectopic eruption of the regular teeth, localised crowding, drifting or impaction of other teeth. However, they may remain impacted for many years without clinical, pathologic or orthodontic complication as well ${ }^{1}$.

\section{Incidence:}

Incidence of supernumerary teeth is approximately 1 in every 110 children with ratio of maxilla to mandible being 8.2 to $1^{2,3}$.

Most commonly seen supernumerary teeth is mesiodens, which is present between two maxillary central incisors, followed by maxillary fourth molars, maxillary paramolar (bucally or lingually to maxillary molars), mandibular premolars, maxillary central incisors, maxillary lateral incisors, mandibular fourth molars, maxillary premolars ${ }^{2}$.

According to Parry and Iyer, incidence of supernumerary premolars is $0.2 \%^{4}$, while Grahnen and Lindhal reported incidence of $9 \%{ }^{5}$. In this case report, a patient with rare bilateral maxillary premolar in $2^{\text {nd }}$ molar region has been presented.

\section{Case Report}

A 18 year old adult reported to the clinic with complaint of forwardly placed teeth in upper and lower front teeth region.

On intra oral examination, two supernumerary teeth were found on either side in $2^{\text {nd }}$ molar region. The supernumerary teeth had erupted palatally between $1^{\text {st }}$ and $2^{\text {nd }}$ molars. The supernumerary teeth appearance was similar to premolars. The $1^{\text {st }}$ and $2^{\text {nd }}$ premolars were present in their normal position in the arch in both the dental quadrants of the maxilla. On palpation and percussion, the supernumerary teeth were asymptomatic. No other abnormal finding was detected.

Family medical history was non contributory and extra oral examination did not show any abnormality. General physician was consulted who ruled out presence of any associated syndrome. Patient was advised for panoramic radiographs (Lateral Cephalogram and Orthopantomogram). No abnormality was detected in the radiographs. Patient was explained about the situation.

The orthodontic treatment plan included extraction of maxillary $1^{\text {st }}$ premolars, banding of $1^{\text {st }}$ and $2^{\text {nd }}$ molars, bonding on remaining teeth, aligning, levelling, and anterior retraction. In order to close the space between $1^{\text {st }}$ and $2^{\text {nd }}$ molar, surgical removal of supernumerary teeth was advised. 


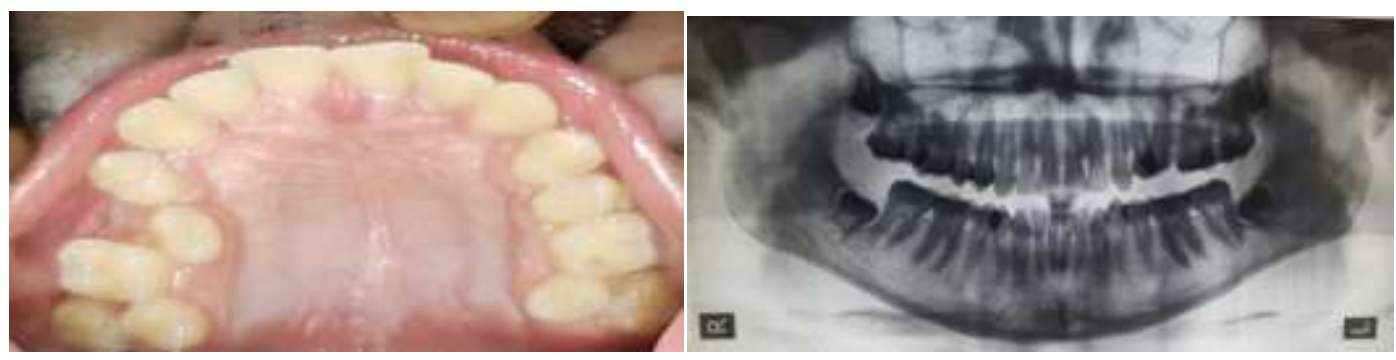

\section{Discussion}

Yusof $^{6}$ in his studies of multiple supernumerary teeth without an associated syndrome has indicated that occurrence of mandibular supernumerary premolars is very common; however the incidence of supernumerary premolars in maxilla is very rare.

Supernumerary teeth in most of the cases are generally asymptomatic and tend to erupt normally. The presence of supernumerary teeth may produce the following problems ${ }^{7}$ :

1) Malocclusion due to disturbance in path of eruption by reducing arch circumference.

2) Prevent eruption of developing teeth.

3) External root resorption of the adjacent teeth due to pressure from erupting supernumerary teeth.

4) A deviated path of eruption may show supernumerary teeth erupting in abnormal locations like nasal cavity, orbit, inferior border of mandible etc. and sometimes weakening of the bone to form a more prone site for fracture.

5) An untreated supernumerary tooth may get transformed into a cyst especially dentigerous cyst.

6) The supernumerary teeth may get fused with the normal teeth thus affecting normal morphology of the involved teeth ${ }^{8,9}$.

The presence of these premolars had caused local irregularities in the form of rotation and spacing adjacent molars.

On examination of adjacent molars, no evidence of root resorption was seen.

The surgical removal of supernumerary teeth was decided to close the space between the $1^{\text {st }}$ and $2^{\text {nd }}$ molar as it would have interfered with the tooth movement in the region. Surgical removal of supernumeraries should be performed with caution to prevent damage to adjacent tooth.

R. Solares ${ }^{10}$ has reported that there is $8 \%$ chance of recurrence of supernumerary premolars after surgical removal.

Detection of supernumerary teeth should be followed by radiographic examination to rule out development or presence of any other supernumerary teeth.

In some cases, these teeth can be utilised to replace congenitally missing or extracted teeth if required.

Yassaei $S .{ }^{11}$ has reported late development of a supernumerary premolar in a case where there was no evidence of supernumerary teeth at the age of 13 in panoramic radiograph.

\section{Conclusion}

Presence of maxillary supernumerary premolar is a rare sight in patients, however on diagnosis, further radiographic investigation should be carried out to check for the presence of other supernumerary teeth. Early interception and treatment should be done to prevent the deleterious effects of supernumerary teeth.

\section{References}

[1] Solares R. The complications of late diagnosis of anterior supernumerary teeth : Case report. J Dent Child. 1990;57:209-211.

[2] Stafne EC. Supernumerary teeth. Dental Cosmos. 1932;74:653-659.

[3] Schulze C. Incidence of supernumerary teeth. Dent Abstr. 1961;6:23.

[4] Parry RR, Iyer VS. Supernumerary teeth amongst orthodontic patients in India. Br Dent J. 1961;111:257-258.

[5] Grahnen H, Lindhal B. Supermumerary teeth in the permanent dentition : A frequency study. Odont Revy. 1961;12:290-294.

[6] Yusof WZ. Non syndrome multiple supernumerary teeth : Literature review. J Can Dent Assoc. 1990;56:147-149.

[7] Primosch RE. Anterior supernumerary teeth- Assessment and surgical intervention in children. Pediatr Dent. 1981;3(2):204-15.

[8] Lawrence WM. Fused primary incisors with succedaneous supernumerary in the area of cleft lip : a case report. Pediatr Dent. 1992;14(6):397-399.

[9] Dowling PA. A case with bilateral paired maxillary supernumerary incisor teeth of supplemental and tuberculate form. Int J Paeditr Dent. 1997;7(2):91-4.

[10] Solares R. Supernumerary premolars : A literature review. Pediatr Dent. 2004;26:450-458.

[11] SoghraYassaei. Late Developing Supernumerary Premolars: Reports of Two Cases. Case Reports in Dentistry, vol. 2013, Article ID 969238, 4 pages, 2013. doi:10.1155/2013/969238 